\title{
Inhibition of enterohemorrhagic Escherichia coli 0157:H7 infection in a gnotobiotic mouse model with pre-colonization by Bacteroides strains
}

\author{
KAZUKI SAITO $^{1}$, RIE SUZUKI ${ }^{1}$, YUKAKO KOYANAGI ${ }^{1}$, \\ HIROSHI ISOGAI $^{2}$, HIROSHI YONEYAMA ${ }^{1}$ and EMIKO ISOGAI ${ }^{1}$ \\ ${ }^{1}$ Department of Animal Microbiology, Graduate School of Agricultural Science, Tohoku University, Sendai, \\ Miyagi 980-8577; ${ }^{2}$ Animal Research Center, Sapporo Medical University, Sapporo, Hokkaido 060-8556, Japan
}

Received December 13, 2018; Accepted February 4, 2019

DOI: $10.3892 /$ br.2019.1193

\begin{abstract}
Enterohemorrhagic Escherichia coli (EHEC) O157:H7 has been known to cause outbreaks of hemorrhagic colitis and hemolytic uremic syndrome. We previously demonstrated that intestinal flora contribute to the prevention of EHEC infection in a mouse model. However, it has not yet been determined whether Bacteroides, a predominant genus in the human intestine, contributes to the prevention of EHEC infection. The aim of the present study was to investigate the effect of Bacteroides fragilis (B. fragilis) and Bacteroides vulgatus (B. vulgatus) on EHEC O157:H7 infection in vivo using gnotobiotic mice. These strains were inoculated into germ-free mice to create a gnotobiotic mouse model. EHEC was inoculated into the mice, which were then monitored for 7 days for any change in symptoms. The mice that had been pre-colonized with the Bacteroides strains did not develop lethal EHEC infection, although several inflammatory symptoms were observed in the $B$. vulgatus pre-colonized group. However, no inflammatory symptoms were identified in the $B$. fragilis pre-colonized group. Moreover, $B$. fragilis exerted an inhibitory effect on enterocyte-like cell apoptosis. B. fragilis protected HT29 cells from apoptosis caused by Shiga toxin. In conclusion, the findings of the present study demonstrated that colonization by Bacteroides strains can inhibit EHEC infection.
\end{abstract}

\section{Introduction}

Enterohemorrhagic Escherichia coli (EHEC) is one of the most common pathogenic intestinal bacteria worldwide. EHEC is a

Correspondence to: Dr Kazuki Saito or Professor Emiko Isogai, Department of Animal Microbiology, Graduate School of Agricultural Science, Tohoku University, 468-1 Aoba, Aramaki, Aoba-ku, Sendai, Miyagi 980-8577, Japan

E-mail: kazuki.saitou.r5@dc.tohoku.ac.jp

E-mail: homeiso2006@yahoo.co.jp

Key words: Bacteroides fragilis, enterohemorrhagic Escherichia coli $\mathrm{O} 157: \mathrm{H} 7$, germ-free mice, intestinal flora food-borne zoonotic pathogen associated with outbreaks that pose a major public health concern worldwide. Once EHEC is ingested, it produces and releases Shiga toxin (Stx) (1). Stx is one of the most important pathogenic factors in EHEC infections (2). Stx binds to globotriaosylceramide (Gb3), which is a Stx receptor expressed in the intestinal epithelium and on the surface of endothelial cells (2). After Stx binds to Gb3, it inhibits protein synthesis and induces cell apoptosis (1). Gb3 is also expressed on vascular endothelial cells and nerve cells. Once Stx enters the bloodstream, it may lead to kidney and brain injury $(3,4)$. Stx comprises Stx1 and Stx2 (1). Stx1 has the same structure as the Shiga toxin produced by Shigella dysenteriae (1), whereas Stx2 has a different structure (5), and it has been reported that Stx2 is associated with the severity of EHEC infection (5). EHEC colonizes the colon and causes diarrhea, hemorrhagic colitis and hemolytic uremic syndrome (HUS) or encephalopathy in humans $(6,7)$. EHEC has several serotypes (8), and EHEC O157:H7 is the strain with the highest rate of isolation (1). In 1982, EHEC O157:H7 was isolated and identified in America as a food-borne pathogen (1). It was the first identification of a food-borne pathogen causing worldwide colitis outbreaks (9). In 1996, a big outbreak of EHEC O157:H7 infection occurred, starting with a school lunch in Japan (10). Therefore, EHEC O157:H7 has been recognized as one of the most serious food-borne pathogens.

In a previous study, it was reported that the susceptibility to EHEC infection varies among different individuals, with infants, children and the elderly being highly susceptible (11). In particular, patients younger than 5 years are at high risk for the development of severe symptoms, such as HUS (11).

Cattle are major carriers of EHEC; however, EHEC colonization in adult ruminants is asymptomatic (1). While EHEC colonizes the colon of humans and forms pathological lesions, it may colonize the recto-anal junction of cattle without Stx-related manifestations (1). The differential susceptibility to Stx and selectivity in colonization sites are associated with host tolerance to EHEC. Cattle transmit EHEC to humans by shedding the pathogen in the feces. Fecal shedding leads to contamination of farm environments by EHEC (12). In a recent study, Wang et al investigated the role of the microbiome in EHEC shedding, and indicated that shedding is 
affected by the composition of the microbiome (12). In particular, it was demonstrated that Firmicutes, Bacteroidetes and Proteobacteria promote EHEC shedding. These phyla also represent the predominant microorganisms in the human and mouse gut microbiome (13). Therefore, it was suggested that these strains may play an important role in EHEC infection in humans and mice.

Intestinal microbiota play an important role in protecting hosts from enteric infections. It has been reported that gastrointestinal microbiota act protectively against enteric infections (14-16). Furthermore, the susceptibility to EHEC infections is affected by the composition of the intestinal microbiome in mice (17). Several studies have investigated the association between specific bacterial strains and EHEC infection (18-23), focusing on probiotic strains. Probiotics are live organisms that, when ingested in adequate amounts, confer a health benefit on the host (24). By protecting the host from pathogen colonization (23) and modulating host immune response (25), probiotic bacteria can contribute to the defense against and recovery from pathogenic infections. In particular, Bifidobacterium and Lactobacillus strains are the predominant and subdominant groups of gastrointestinal microbiota, respectively (26). These strains are the most widely used probiotic bacteria and are included in a number of functional foods and dietary supplements (26-28). Bifidobacterium and Lactobacillus are highly relevant for the prevention of tissue invasion by enteropathogens (29).

It was recently reported that the ratio of Bacteroides in intestinal microbiota gradually increases with aging (30). Bacteroides is one of the most predominant microbial genera within the gastrointestinal tract (31). Furthermore, Bacteroides exerts negative effects on their hosts $(31,32)$. It is generally considered that Bacteroides may promote infections and cause inflammatory diarrhea and ulcerative colitis, among others (33-35). However, to the best of our knowledge, the association between Bacteroides and EHEC infection has not yet been reported.

The aim of the present study was to examine the association between Bacteroides and EHEC infections. Two Bacteroides strains were used, namely $B$. fragilis and $B$. vulgatus. These strains generally promote infections (33-35). However, a recent study demonstrated that $B$. fragilis can modulate the host immune system (36), exerting not only negative but also positive effects on the host. Therefore, to elucidate the role of Bacteroides in intestinal microbiota, the association between Bacteroides and EHEC infection was investigated.

\section{Materials and methods}

Bacterial strains, media and cultures. EHEC O157:H7 EDL931k was obtained from the EDL931 strain (37). B. fragilis RIMD0230001 and Bacteroides vulgatus JCM5826 were the strains of Bacteroides used in the present study $(36,38)$. EHEC and Bacteroides were propagated in $10 \mathrm{ml}$ of brain heart infusion (BHI) medium (Difco Laboratories, Detroit, MI, USA) and Gifu Anaerobic Medium (GAM) broth (Nissui Pharmaceutical Co., Tokyo, Japan), respectively. All bacteria were incubated anaerobically in Anaero-Pack systems (Mitsubishi Gas Chemical, Tokyo, Japan) at $37^{\circ} \mathrm{C}$ for $24 \mathrm{~h}$. The
Table I. Definition of low, medium and high level of EHEC CFU, and Stx 1 and Stx2.

\begin{tabular}{lcc}
\hline Level & $\begin{array}{c}\text { Number of EHEC } \\
\left(\log _{10} \text { CFU/ml }\right)\end{array}$ & Stx1 and Stx2 \\
\hline High & $\geq 9.0$ & $\geq 30.0$ \\
Medium & $7.0-8.9$ & $10.0-39.9$ \\
Low & $\leq 6.9$ & $\leq 9.9$ \\
\hline
\end{tabular}

EHEC, enterohemorrhagic Escherichia coli; CFU, colony-forming units; Stx, Shiga toxin.

BHI and GAM media were sterilized at $121^{\circ} \mathrm{C}$ for $15 \mathrm{~min}$ and $115^{\circ} \mathrm{C}$ for $15 \mathrm{~min}$, respectively.

Animals. Male germ-free (GF) mice (IQI/Jic, 5 weeks old) were obtained from Japan Clea Co. Ltd (Tokyo, Japan). Each group of mice was housed in a cage with a $\mathrm{BBH}$ box isolator on a $12: 12$ light:dark cycle at $24 \pm 2^{\circ} \mathrm{C}$ under aseptic conditions. The mice were provided autoclaved diet and water ad libitum.

Cell culture. Enterocyte-like HT29 cells (39) were used for analysis with the MUSE Cell Analyzer (Merck KGaA, Darmstadt, Germany). HT29 cells were obtained from American Type Culture Collection (Manassas, VA, USA). Cells were routinely grown in Dulbecco's modified Eagle's minimal essential medium (DMEM) (Nacalai Tesque, Inc., Kyoto, Japan) supplemented with $10 \%$ sterilized fetal bovine serum (Valley Biomedical, Inc., Winchester, VA, USA) and $1 \%$ antibiotic/antimycotic mixed stock solution (Nacalai Tesque, Inc.). HT29 cells were incubated in $5 \% \mathrm{CO}_{2}$ at $37^{\circ} \mathrm{C}$. Cell treatment was performed as previously described (40).

Inoculation and EHEC infection. The EHEC infection protocols were based on the methods described by Isogai et al (41). The mice were divided into 6 groups as follows: $B$. fragilis pre-colonized group (with or without EHEC inoculation), B. vulgatus pre-colonized group (with or without EHEC inoculation), EHEC mono-colonized group and medium-only-inoculated mice. The EHEC mono-colonized group and medium-only-inoculated mice were used at the same time by Koyanagi et al (unpublished data).

The strains of Bacteroides were incubated overnight at $37^{\circ} \mathrm{C}$ under anaerobic conditions and suspended at a concentration of $10^{8}$ colony-forming units (CFU)/ml in sterile Dulbecco's phosphate-buffered saline (D-PBS) (Nissui Pharmaceutical). The suspension of Bacteroides strains (100 $\mu \mathrm{l} /$ mouse) was inoculated orally through a soft polyethylene catheter that was immediately removed. After $24 \mathrm{~h}$ of Bacteroides strain inoculation, $100 \mu \mathrm{l}$ of the EHEC suspension $\left(1.0 \times 10^{7} \mathrm{CFU} / \mathrm{ml}\right)$ or sterile BHI medium were inoculated in each mouse using the same method. Seven days after EHEC inoculation, the mice were sacrificed by cervical dislocation.

Histopathological analysis. The mouse kidneys and intestines were fixed overnight in $10 \%$ formaldehyde at $\sim 25^{\circ} \mathrm{C}$ and the 
Table II. Effects of bacterial colonization on mouse lethality 7 days after EHEC O157:H7 infection.

\begin{tabular}{lcccc}
\hline & & & \multicolumn{2}{c}{ No. of mice } \\
\cline { 3 - 5 } Groups & $\begin{array}{c}\text { EHEC } \\
\text { inoculation }\end{array}$ & $\begin{array}{c}\text { Total no. } \\
\text { of mice }\end{array}$ & Dead & $\begin{array}{c}\text { Exhibiting intestinal edema } \\
\text { and hemorrhagic lesions }\end{array}$ \\
\hline B. fragilis pre-colonized group & + & 5 & $0^{\mathrm{a}}$ & $0^{\mathrm{a}}$ \\
B. vulgatus pre-colonized group & - & 5 & 0 & 0 \\
EHEC mono-colonized group & - & 4 & 1 & 4 \\
Medium-only-inoculated mice & + & 4 & 0 & 4 \\
\end{tabular}

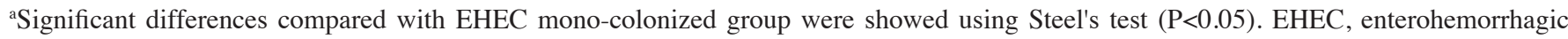
Escherichia coli.

tissues were embedded in paraffin and stained with hematoxylin and eosin.

Confirmation of EHEC translocation to organs. Seven days after EHEC inoculation, the mice were dissected and the lungs, liver, spleen, brain and heart were removed. The sections of these organs were stamped on CHROMagar ${ }^{\mathrm{TM}} \mathrm{O} 157$ for the detection of EHEC O157:H7 (CHROMagar Microbiology, Paris, France). After incubation for $48 \mathrm{~h}$ at $37^{\circ} \mathrm{C}$ under aerobic conditions, colony formation was examined.

EHEC count and Stx detection in mouse fecal samples. At 1, 3 and 7 days after the inoculation of EHEC, feces were collected from mice in different groups. Fecal samples were suspended in BHI broth at a 1:19 (w/v) ratio. To quantify the number of colonized EHEC, fecal suspensions were serially diluted and plated on CHROMagar ${ }^{\mathrm{TM}} \mathrm{O} 157$ for detection of EHEC O157:H7. After $48 \mathrm{~h}$ of anaerobic incubation at $37^{\circ} \mathrm{C}$, the CFU/ml of EHEC 0157:H7 was determined. Stx1 and Stx2 titers were qualified using a verotoxin detection kit based on reserved passive latex agglutination (Denka Seikan Co., Ltd., Tokyo, Japan). The fecal suspensions were centrifuged at $900 \mathrm{x} \mathrm{g}$ for $10 \mathrm{~min}$ at room temperature, and the supernatant was used for Stx1 and Stx 2 detection. The number of EHEC and the levels of Stx1 and Stx2 we defined as low, medium and high. The ranges are defined and provided in Table I.

Suppression of apoptosis caused by Stx using Annexin $V$ and 7-AAD combination assays. Muse Annexin V and Dead Cell kit (Merck KGaA) was used for the detection of apoptosis in this experiment. This kit has been used previously for sensitive detection of apoptosis $(42,43)$. HT29 cells were seeded at a density of $1.0 \times 10^{5}$ cells/well in a 12 -well plate and incubated at $37^{\circ} \mathrm{C}$ and $5 \% \mathrm{CO}_{2}$ until reaching confluence. The DMEM was replaced with $900 \mu \mathrm{l}$ fresh medium without antibiotic/antimycotic mixed stock solution $30 \mathrm{~min}$ prior to bacterial inoculation. Culture solutions of Bacteroides strains incubated in GAM broth overnight were adjusted to $1.5 \times 10^{8} \mathrm{CFU} / \mathrm{ml}$ and resuspended in PBS. Following incubation for $30 \mathrm{~min}$ in DMEM without antibiotic/antimycotic mixed stock solution, $1 \mathrm{ml}$ Bacteroides suspension was inoculated into the cells.
Similarly, culture solutions of EHEC incubated in BHI broth overnight were adjusted to $1.5 \times 10^{8} \mathrm{CFU} / \mathrm{ml}$ and resuspended in PBS. After $1 \mathrm{~h}$ of incubation, $100 \mu \mathrm{l}$ EHEC suspension was inoculated into the cells. After $9 \mathrm{~h}$, the culture supernatants were collected for Stx detection, as described above. Subsequently, the cells were washed 3 times with $1 \mathrm{ml}$ PBS, treated with trypsin and transferred into microtubes. The cells were centrifuged at $800 \mathrm{x} \mathrm{g}$ for $5 \mathrm{~min}$ and resuspended in $100 \mu \mathrm{l}$ fresh DMEM. A total of $100 \mu \mathrm{l}$ Annexin $\mathrm{V}$ and Dead Cell Dye assay reagent (Merck KGaA) were added to the samples and mixed. After incubation for $20 \mathrm{~min}$ at room temperature in the dark, the samples were applied to the Muse Cell Analyzer (Merck KGaA).

Statistical analysis. Significant differences in lethality and EHEC translocation were calculated using the Steel's test. Furthermore, the statistical differences in EHEC viable counts, Stx levels in fecal samples and apoptotic cells in the co-culture of Bacteroides and EHEC were determined by Dunnett's test or the Tukey-Kramer test. Significant differences were defined as probability values of $<0.05$. Experiments in vitro were performed in triplicates or more.

\section{Results}

Prevention of EHEC infection-related lethality by Bacteroides colonization. The effect of intestinal Bacteroides strains against EHEC infection was examined using GF mice. Colonization with $B$. fragilis was found to significantly decrease the lethality of EHEC infection $(\mathrm{P}<0.05$; Table II). In the B. fragilis pre-colonized group, all mice survived until day 7 , whereas in the B. vulgatus pre-colonized group, $25 \%$ of the mice died within the first 5 days while the rest survived until day 7 . However, all the mice in the EHEC-mono-colonized group had died by day 5 . All the mice of the EHEC-mono-colonized and B. vulgatus pre-colonized groups exhibited intestinal edema and hemorrhagic lesions (Table II).

Suppressive effects of colonization by Bacteroides strains on the histopathological changes in the intestine and kidney. As determined by histological analysis, B. fragilis protected 
Table III. Effects of bacterial colonization on EHEC translocation to organs.

\begin{tabular}{|c|c|c|c|c|c|c|}
\hline \multirow[b]{2}{*}{ Groups } & \multirow[b]{2}{*}{ EHEC inoculation } & \multirow[b]{2}{*}{ Total no. of mice } & \multicolumn{4}{|c|}{$\begin{array}{c}\text { No. of mice detected } \\
\text { with EHEC in each organ }\end{array}$} \\
\hline & & & Heart & Liver & Spleen & Kidney \\
\hline \multirow[t]{2}{*}{ B. fragilis-colonized group } & + & 5 & 0 & 0 & 0 & 0 \\
\hline & - & 5 & 0 & 0 & 0 & 0 \\
\hline \multirow[t]{2}{*}{ B. vulgatus-colonized group } & + & 4 & 1 & 2 & 3 & 1 \\
\hline & - & 4 & 0 & 0 & 0 & 0 \\
\hline EHEC-infected GF mice & + & 4 & 2 & 3 & 3 & 3 \\
\hline Medium-only-inoculated mice & - & 3 & 0 & 0 & 0 & 0 \\
\hline
\end{tabular}

EHEC, enterohemorrhagic Escherichia coli; GF, germ-free.
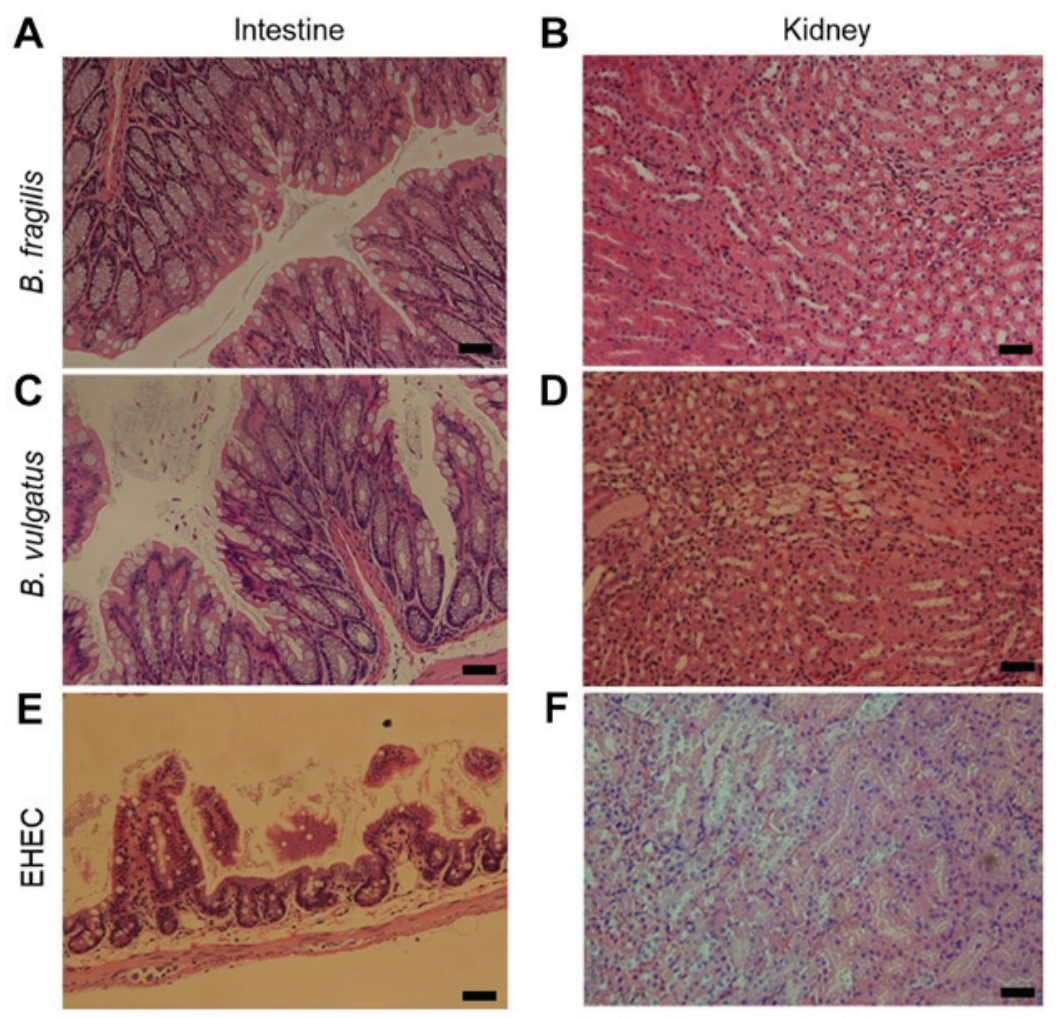

Figure 1. Histopathological changes in the intestine and kidney. Hematoxylin and eosin staining of the (A, C and E) intestine and (B, D and F) kidney in mice infected with EHEC. Panels A and B, B. fragilis-colonized mouse almost fully suppressed the inflammatory symptoms. Panels C and D, B. vulgatus-colonized mouse exhibited neutrophil migration in the intestine and cytopathic alterations in the kidneys. Panels E and F, EHEC-mono-colonized mouse showed shedding of epithelial cells in the intestine and necrosis of renal tubules in the kidney. Bars, $50.0 \mu \mathrm{m}$. EHEC, enterohemorrhagic Escherichia coli.

the host from the development of histopathological lesions and almost fully suppressed the inflammatory symptoms caused by EHEC inoculation (Fig. 1A and B). B. vulgatus also protected the host from death following EHEC inoculation (Table II); however, neutrophil migration was observed in the intestine and cytopathic changes were observed in the kidneys (Fig. 1C and D). In the EHEC mono-colonized group, shedding of epithelial cells was observed in the intestine, and necrosis of renal tubules was observed in the kidney (Fig. 1E and F).

Suppression of EHEC translocation to other organs by Bacteroides colonization. In the $B$. fragilis pre-colonized group, no translocation of EHEC was observed (Table III). However, in the B. vulgatus pre-colonized and EHEC-mono-colonized groups, EHEC translocation to other organs, such as the heart, liver, spleen and kidney, was observed. When comparing the translocation rate between B. vulgatus and the EHEC group, translocation in the EHEC mono-colonized group was higher compared with that in the B. vulgatus pre-colonized group, but the difference between the two groups was not statistically significant $(\mathrm{P}=0.13)$.

Comparison of the effects of Bacteroides colonization on viable counts of EHEC O157:H7. On day 1, the EHEC viable count in 
Table IV. Excretion levels of EHEC, Stx1 and Stx2 in the feces.

\begin{tabular}{|c|c|c|c|c|c|c|c|}
\hline \multirow[b]{3}{*}{ Groups } & \multirow[b]{3}{*}{ EHEC inoculation } & \multirow[b]{3}{*}{ Total no. of mice } & \multirow{3}{*}{$\begin{array}{c}\begin{array}{c}\text { EHEC } \\
\text { colonization } \\
\text { level }\end{array} \\
{\text { Day } 1^{\mathrm{a}}}^{\text {Dation }}\end{array}$} & \multicolumn{4}{|c|}{ Stx level in the feces } \\
\hline & & & & \multicolumn{2}{|c|}{ Stx 1} & \multicolumn{2}{|c|}{ Stx 2} \\
\hline & & & & Day 3 & Day 7 & Day 3 & Day 7 \\
\hline \multirow[t]{2}{*}{ B. fragilis-colonized group } & + & 5 & $\mathrm{~L}$ & $\mathbf{M}^{\mathrm{b}}$ & $\mathrm{L}$ & $\mathrm{M}^{\mathrm{b}}$ & $\mathrm{L}$ \\
\hline & - & 5 & ND & ND & ND & ND & ND \\
\hline \multirow[t]{2}{*}{ B. vulgatus-colonized group } & + & 4 & M & $\mathbf{M}^{\mathrm{b}}$ & M & $\mathrm{H}^{\mathrm{b}}$ & M \\
\hline & - & 4 & ND & ND & ND & ND & ND \\
\hline EHEC-colonized group & + & 4 & $\mathrm{H}$ & $\mathrm{H}^{\mathrm{c}}$ & NT & $\mathrm{H}^{\mathrm{c}}$ & NT \\
\hline Medium-only-inoculated group & - & 3 & ND & ND & ND & ND & ND \\
\hline
\end{tabular}

${ }^{a}$ Data of days 3 and 7 not shown as no significant differences were observed among groups. Stx levels are shown as final dilution \pm standard deviation. H, high; M, medium and L, low (Table I). EHEC, enterohemorrhagic Escherichia coli; Stx, Shiga toxin; ND, not detected; NT, not tested due to death. ${ }^{\text {b,c }}$ No significant difference at the $99 \%$ confidence level, using the Tukey-Kramer test.

the $B$. fragilis pre-colonized group was lower compared with that in the EHEC mono-inoculated group $(\mathrm{P}=0.0538)$, although the difference was not significant (Table IV). However, the EHEC count gradually increased from day 3 to day 7 . In the $B$. vulgatus pre-colonized group, no significant differences were observed among the different time points. Furthermore, the EHEC count in the EHEC-mono-colonized group was not examined on day 7 , as all the mice had died by day 5 following EHEC inoculation.

Inhibitory effects of colonization by Bacteroides strains on Stx1 and Stx2 levels in fecal samples. In the B. fragilis pre-colonized group, Stx1 and Stx 2 levels were significantly lower compared with those in the EHEC mono-colonized group on day 3 (Table IV). Furthermore, in the B. vulgatus pre-colonized group, the Stx1 level was significantly lower compared with that in the EHEC group. By contrast, no significant differences were observed in Stx2 levels between the B. vulgatus pre-colonized and the EHEC-mono-colonized groups on day 3. EHEC mono-colonized mice exhibited $>10$-fold higher Stx2 levels compared with mice colonized with Bacteroides. The Stx levels in the EHEC mono-colonized group were not tested on day 7 , as all the mice had died by day 5 following EHEC inoculation.

Detection of apoptosis of HT29cellsco-cultured withBacteroides strains and EHEC. The apoptosis of epithelial cells was detected to investigate the factors mediating the protective effects of Bacteroides strains in vitro. EHEC O157:H7 is generally known to promote apoptosis of intestinal epithelial cells $(1,44)$. However, in this experiment, in the $B$. fragilis-colonized group, no tissue lesions were observed in the small intestine (Fig. 1A), suggesting that $B$. fragilis exerted inhibitory effects on the apoptosis of epithelial cells. Therefore, the inhibitory effect of apoptosis was further examined in the $B$. fragilis strain.

In the B. fragilis and B. vulgatus mono-colonized groups, the majority of cells were non-apoptotic (Fig. 2A and B). However, in the EHEC-mono-colonized group, most cells were apoptotic or necrotic. Mono-colonization by EHEC was significantly increased during early apoptosis (Fig. 2C;
$\mathrm{P}<0.01)$. Interestingly, co-culture with $B$. fragilis and EHEC significantly decreased the apoptotic cell percentage $(\mathrm{P}<0.01)$. However, co-culture with B. vulgatus and EHEC did not significantly affect apoptosis. Furthermore, Stx1 and Stx2 production by EHEC was not significantly suppressed in cells co-cultured with B. fragilis or B. vulgatus (Fig. 3).

\section{Discussion}

It has been reported that $B$. fragilis contributes to diarrheal disease in animals and humans (31), and that B. vulgatus is pathogenic in individuals with underlying conditions, such as patients with ulcerative colitis (45). In the present study, we demonstrated the protective effects of Bacteroides against EHEC infection. The findings of the study revealed that intestinal flora are implicated in the susceptibility to EHEC infection. In fact, GF mice inoculated with EHEC displayed severe symptoms and high lethality (Fig. 1, Table I). By contrast, colonization by a single Bacteroides strain exerted a protective effect. B. fragilis suppressed lethality from EHEC infection. Similarly, B. vulgatus suppressed EHEC lethality, albeit to a lesser extent. Furthermore, the EHEC count in the intestines of mice colonized by B. fragilis or B. vulgatus was reduced, although the difference was not significant (Table IV). Moreover, Stx production in the mouse intestine was significantly suppressed in the $B$.fragilis-colonized group (Table IV). These results demonstrated that $B$. fragilis and $B$. vulgatus effectively decreased the lethality of EHEC infection (Table II), particularly in the B. fragilis pre-colonized group $(\mathrm{P}<0.05)$. In the present study, the mechanisms by which each bacterium protected mice from EHEC infection were not fully elucidated. However, to the best of our knowledge, this study is the first to demonstrate that Bacteroides strains may act protectively against lethal EHEC infection in mice.

Our study suggested that the EHEC count in the early stages of EHEC infection is a key factor affecting the severity of the infection. Frankel et al reported that the locus of enterocyte effacement type III secretion system of EHEC is crucial for bacterial adhesion to the host's intestinal cells during the 


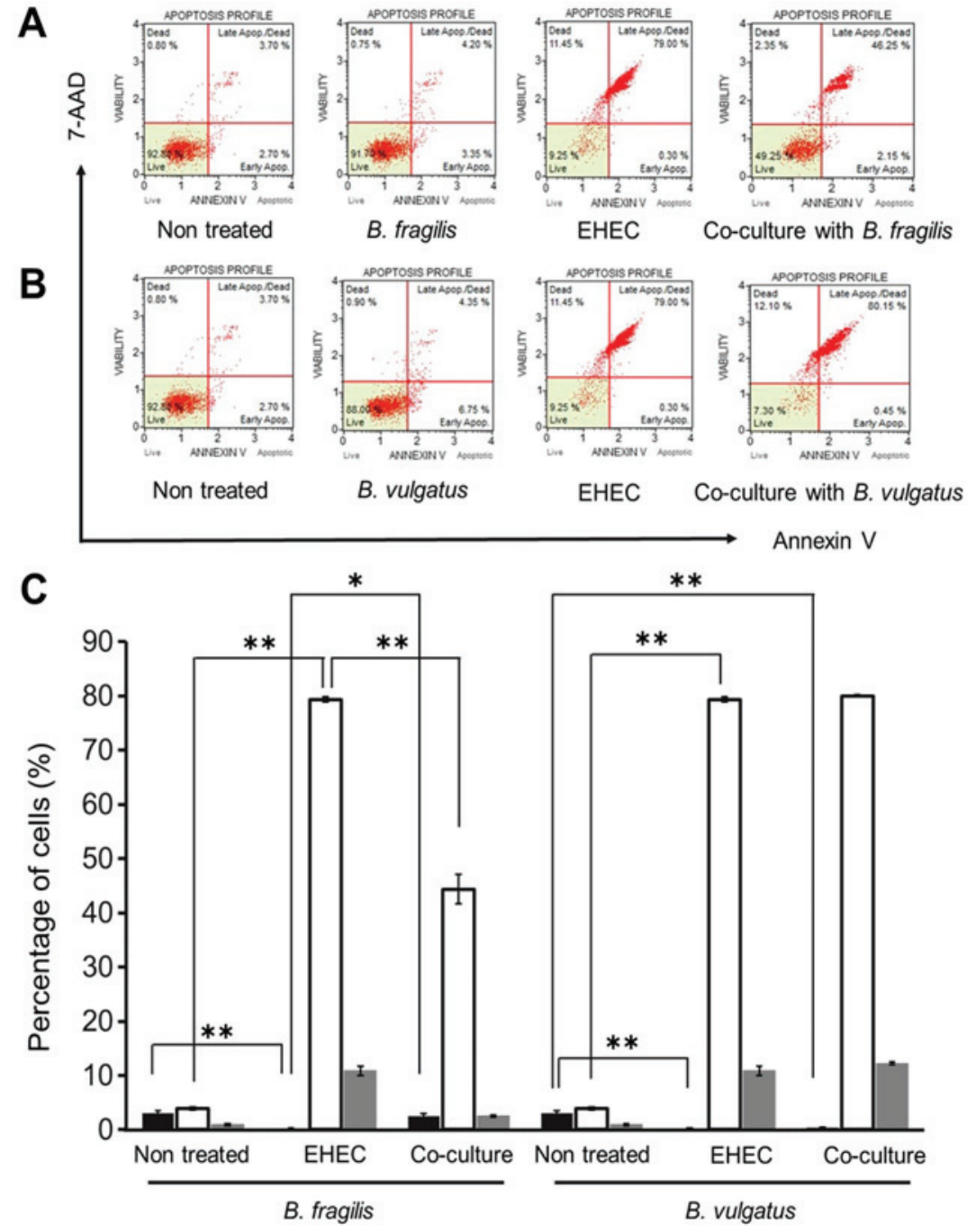

Figure 2. Detection of apoptosis in the EHEC mono-colonized and EHEC co-cultured with Bacteroides strains groups using flow cytometric analysis of apoptotic cells (n=3). (A and B) Results in non-treated HT29 cells, HT29 cells infected with EHEC, HT29 cells cultured with Bacteroides strains (A; B. fragilis, B; B. vulgatus), and HT29 cells infected with EHEC and prophylactically co-cultured with Bacteroides strains (A; B. fragilis, B; B. vulgatus). (C) Percentage of early apoptotic cells (black bar), late apoptotic or necrotic cells (white bar) and necrotic cells (gray bar). ${ }^{* *} \mathrm{P}<0.01$ and ${ }^{*} \mathrm{P}<0.05$, statistically significant as calculated by the Tukey-Kramer test. Data are shown as mean \pm standard deviation of three different experiments. EHEC, enterohemorrhagic Escherichia coli.

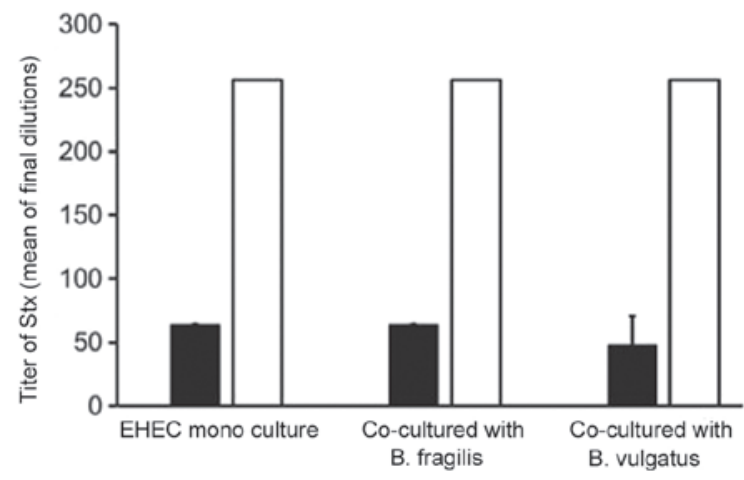

Figure 3. Quantification of Stx1 (black bar) and Stx2 (white bar) levels in the EHEC mono-colonized and EHEC co-cultured with Bacteroides strains groups $(n=3)$. Data are shown as mean \pm standard deviation of three different experiments. The Tukey-Kramer test revealed no statistically significant differences. EHEC, enterohemorrhagic Escherichia coli.

early stages of infection (46). Adhesion to the epithelial cells enables disease establishment (47). The results of our study demonstrated that $B$. fragilis lowered the EHEC count in vivo ( $\mathrm{P}=0.0538$; Table IV). In addition, $B$. fragilis fully protected the host from EHEC infection and suppressed the formation of pathological lesions (Fig. 1A and B; Table II). However, $B$. vulgatus did not lower the EHEC count in the early stages of infection (Table IV) and did not completely suppress the development of symptoms (Table II). Therefore, the type of Bacteroides colonization and the early stages of the EHEC infection are key factors in determining disease severity.

The present study also demonstrated that translocation may be another factor associated with the severity of EHEC infection. Generally, EHEC is taken up orally and colonizes the intestinal tract (1). Considering the route of EHEC translocation, if the barrier of the intestinal tract wall is compromised, Stx can circulate in the entire body. Fukuda et al reported that Stx translocation is associated with EHEC infection lethality (23). In the present study, the B. fragilis-colonized group did not exhibit EHEC translocation to the other organs examined (Table III), and there were no pathological lesions identified (Fig. 1). However, in the B. vulgatus pre-colonized 
and EHEC-mono-colonized groups, EHEC translocation was observed in all the organs examined (Table III). In addition, the EHEC-mono-colonized group displayed the highest ratio of EHEC translocation in each organ (Table III). Furthermore, Stx levels in the feces were examined and the B. fragilis pre-colonized group exhibited the lowest Stx level among all groups (Table IV). Therefore, the findings of the present study demonstrated that $B$. fragilis suppressed the susceptibility to EHEC infection.

Protecting the intestinal tract helps prevent lethal EHEC infections (16). Stx produced by EHEC promotes apoptosis of intestinal epithelial cells (23). Inhibition of Stx circulation in the body is crucial for the prevention of lethal EHEC infection (16). In the present study, the inhibitory effect of Bacteroides on epithelial intestinal cell apoptosis was demonstrated (Fig. 2). In the EHEC-mono-colonized group, the majority of the cells were apoptotic in vitro (Fig. 2C). However, in the B. fragilis-co-cultured group, apoptosis of HT29 cells was significantly reduced $(\mathrm{P}<0.01$; Fig. $2 \mathrm{C})$, whereas apoptosis was not suppressed in the $B$. vulgatus-co-culture group (Fig. 2C). Of note, Stx production was not found to be significantly suppressed following apoptosis analysis (Fig. 3). The reason apoptosis was suppressed in HT29 cells remains unclear, and the underlying mechanisms were not elucidated in the present study. However, B. fragilis was confirmed to exert an inhibitory effect on intestinal epithelial cell apoptosis.

In conclusion, the present study demonstrated that Bacteroides prevented EHEC infection. It was also suggested that Bacteroides may be associated with susceptibility to EHEC infection in mice, in addition to cattle. Our findings using single-flora systems demonstrated that Bacteroides contributed to the prevention of EHEC infection, and B. fragilis was shown to fully protect against EHEC infection. The interaction between EHEC and Bacteroides in GF mice provides little information regarding their behavior in the microbiome. However, understanding the role of each intestinal bacterium is relevant when considering treatment against EHEC infection. Further studies are required to elucidate the mechanism underlying the protective role of $B$. fragilis against EHEC infection.

\section{Acknowledgements}

We would like to thank our laboratory staff for helpful discussions and support.

\section{Funding}

The present study was supported by a Grant-in-Aid for Scientific Research from Yakult Bio-Science Foundation.

\section{Availability of data and materials}

All data generated or analyzed during the present study are included in this published article.

\section{Ethics approval and consent to participate}

Each experimental protocol was performed in accordance with the Regulations for Animal Experiments and Related Activities at Tohoku University (approval no. 2011AgA-30).

\section{Patient consent for publication}

Not applicable.

\section{Authors' contributions}

KS, RS, HI and EI performed the experiments; KS, RS, YK and EI designed the study; KS, YK, HY and EI wrote the manuscript.

\section{Competing interests}

The authors declare that they have no competing interests to disclose.

\section{References}

1. Nguyen Y and Sperandio V: Enterohemorrhagic E. coli (EHEC) pathogenesis. Front Cell Infect Microbiol 2: 90, 2012.

2. Jones NL, Islur A, Haq R, Mascarenhas M, Karmali MA, Perdue MH, Zanke BW and Sherman PM: Escherichia coli Shiga toxins induce apoptosis in epithelial cells that is regulated by the Bcl-2 family. Am J Physiol Gastrointest Liver Physiol 278: G811-G819, 2000.

3. Hughes AK, Stricklett PK, Schmid D, Kohan DE and Hughes AK: Cytotoxic effect of Shiga toxin-1 on human glomerular epithelial cells. Kidney Int 57: 2350-2359, 2000.

4. Rutjes NW, Binnington BA, Smith CR, Maloney MD and Lingwood CA: Differential tissue targeting and pathogenesis of verotoxins 1 and 2 in the mouse animal model. Kidney Int 62: $832-845,2002$

5. O'Brien AD and Holmes RK: Shiga and Shiga-like toxins. Microbiol Rev 51: 206-220, 1987.

6. Karmali MA, Steele BT, Petric M and Lim C: Sporadic cases of haemolytic-uraemic syndrome associated with faecal cytotoxin and cytotoxin-producing Escherichia coli in stools. Lancet 1: 619-620, 1983 .

7. Yoshimitsu M, Hayashi N, Kaneko Y and Doyama H: An adult case of combined encephalopathy and hemolytic uremic syndrome caused by Escherichia coli O157. Nihon Shokakibyo Gakkai Zasshi 108: 74-79, 2011.

8. Gyles CL: Shiga toxin-producing Escherichia coli: An overview. J Anim Sci 85 (Suppl): E45-E62, 2007.

9. Remis RS, MacDonald KL, Riley LW, Puhr ND, Wells JG, Davis BR, Blake PA and Cohen ML: Sporadic cases of hemorrhagic colitis associated with Escherichia coli O157:H7. Ann Intern Med 101: 624-626, 1984

10. Fukushima H, Hashizume T, Morita Y, Tanaka J, Azuma K, Mizumoto Y, Kaneno M, Matsuura M, Konma K and Kitani T: Clinical experiences in Sakai City Hospital during the massive outbreak of enterohemorrhagic Escherichia coli O157 infections in Sakai City, 1996. Pediatr Int 41: 213-217, 1999.

11. Terajima J, Izumiya $\mathrm{H}$, Wada $\mathrm{A}$, Tamura $\mathrm{K}$ and Watanabe $\mathrm{H}$ : Shiga toxin-producing Escherichia coli O157:H7 in Japan. Emerg Infect Dis 5: 301-302, 1999.

12. Wang O, McAllister TA, Plastow G, Stanford K, Selinger B and Guan LL: Interactions of the Hindgut Mucosa-Associated Microbiome with Its Host Regulate Shedding of Escherichia coli O157:H7 by Cattle. Appl Environ Microbiol 84: pii: e01738-17, 2017.

13. Ley RE, Bäckhed F, Turnbaugh P, Lozupone CA, Knight RD and Gordon JI: Obesity alters gut microbial ecology. Proc Natl Acad Sci USA 102: 11070-11075, 2005.

14. Momose Y, Hirayama K and Itoh K: Effect of organic acids on inhibition of Escherichia coli O157:H7 colonization in gnotobiotic mice associated with infant intestinal microbiota. Antonie van Leeuwenhoek 93: 141-149, 2008.

15. Yoshimura K, Matsui T and Itoh K: Prevention of Escherichia coli $\mathrm{O} 157: \mathrm{H} 7$ infection in gnotobiotic mice associated with Bifidobacterium strains. Antonie van Leeuwenhoek 97: 107-117, 2010.

16. de Sablet T, Chassard C, Bernalier-Donadille A, Vareille M, Gobert AP and Martin C: Human microbiota-secreted factors inhibit shiga toxin synthesis by enterohemorrhagic Escherichia coli O157:H7. Infect Immun 77: 783-790, 2009. 
17. Momose Y, Hirayama K and Itoh K: Antagonism of intestinal bacteria isolated from human infants against Escherichia coli O157:H7 infection in gnotobiotic mice. Microb Ecol Health Dis 17: 9-14, 2005.

18. Asahara T, Shimizu K, Nomoto K, Hamabata T, Ozawa A and Takeda Y: Probiotic bifidobacteria protect mice from lethal infection with Shiga toxin-producing Escherichia coli O157:H7. Infect Immun 72: 2240-2247, 2004.

19. Chen YP, Lee TY, Hong WS, Hsieh HH and Chen MJ: Effects of Lactobacillus kefiranofaciens M1 isolated from kefir grains on enterohemorrhagic Escherichia coli infection using mouse and intestinal cell models. J Dairy Sci 96: 7467-7477, 2013.

20. Rund SA, Rohde H, Sonnenborn U and Oelschlaeger TA: Antagonistic effects of probiotic Escherichia coli Nissle 1917 on EHEC strains of serotype O104:H4 and O157:H7. Int J Med Microbiol 303: 1-8, 2013

21. Eaton KA, Honkala A, Auchtung TA and Britton RA: Probiotic Lactobacillus reuteri ameliorates disease due to enterohemorrhagic Escherichia coli in germfree mice. Infect Immun 79: 185-191, 2011.

22. Ogawa M, Shimizu K, Nomoto K, Takahashi M, Watanuki M, Tanaka R, Tanaka T, Hamabata T, Yamasaki S and Takeda Y: Protective effect of Lactobacillus casei strain Shirota on Shiga toxin-producing Escherichia coli $\mathrm{O} 157: \mathrm{H} 7$ infection in infant rabbits. Infect Immun 69: 1101-1108, 2001.

23. Fukuda S, Toh H, Hase K, Oshima K, Nakanishi Y, Yoshimura K, Tobe T, Clarke JM, Topping DL, Suzuki T, et al: Bifidobacteria can protect from enteropathogenic infection through production of acetate. Nature 469: 543-547, 2011.

24. Food and Agriculture Organization of United Nations and World Health Organization Working Group Report: Guidelines for the evaluation of probiotics in food. FAO/WHO, London, ON, 2002.

25. Resta-Lenert $S$ and Barrett KE: Live probiotics protect intestinal epithelial cells from the effects of infection with enteroinvasive Escherichia coli (EIEC). Gut 52: 988-997, 2003.

26. Shreiner AB, Kao JY and Young VB: The gut microbiome in health and in disease. Curr Opin Gastroenterol 31: 69-75, 2015.

27. Macpherson AJ and Harris NL: Interactions between commensal intestinal bacteria and the immune system. Nat Rev Immunol 4 478-485, 2004

28. Frick JS, Schenk K, Quitadamo M, Kahl F, Köberle M, Bohn E, Aepfelbacher M and Autenrieth IB: Lactobacillus fermentum attenuates the proinflammatory effect of Yersinia enterocolitica on human epithelial cells. Inflamm Bowel Dis 13: 83-90, 2007.

29. Kang HJ and Im SH: Probiotics as an Immune Modulator. J Nutr Sci Vitaminol (Tokyo) 61 (Suppl): S103-S105, 2015.

30. Mariat D, Firmesse O, Levenez F, Guimarăes V, Sokol H, Doré J, Corthier G and Furet JP: The Firmicutes/Bacteroidetes ratio of the human microbiota changes with age. BMC Microbiol 9: 123, 2009.

31. Border M, Firehammer BD, Shoop DS and Myers LL: Isolation of Bacteroides fragilis from the feces of diarrheic calves and lambs. J Clin Microbiol 21: 472-473, 1985.

32. Kim JM, Lee JY and Kim YJ: Inhibition of apoptosis in Bacteroides fragilis enterotoxin-stimulated intestinal epithelial cells through the induction of c-IAP-2. Eur J Immunol 38 : 2190-2199, 2008

33. Chen LA, Van Meerbeke S, Albesiano E, Goodwin A, Wu S, Yu H, Carroll K and Sears C: Fecal detection of enterotoxigenic Bacteroides fragilis. Eur J Clin Microbiol Infect Dis 34: 1871-1877, 2015

34. Onderdonk AB, Bronson R and Cisneros R: Comparison of Bacteroides vulgatus strains in the enhancement of experimental ulcerative colitis. Infect Immun 55: 835-836, 1987.
35. Rashidan M, Azimirad M, Alebouyeh M, Ghobakhlou M, Asadzadeh Aghdaei $\mathrm{H}$ and Zali MR: Detection of B. fragilis group and diversity of bft enterotoxin and antibiotic resistance markers cepA, cfiA and nim among intestinal Bacteroides fragilis strains in patients with inflammatory bowel disease. Anaerobe 50: 93-100, 2018

36. Mazmanian SK, Liu CH, Tzianabos AO and Kasper DL: An immunomodulatory molecule of symbiotic bacteria directs maturation of the host immune system. Cell 122: 107-118, 2005.

37. Riley LW, Remis RS, Helgerson SD, McGee HB, Wells JG Davis BR, Hebert RJ, Olcott ES, Johnson LM, Hargrett NT, et al: Hemorrhagic colitis associated with a rare Escherichia coli serotype. N Engl J Med 308: 681-685, 1983.

38. Li J, Mandal G and Rosen BP: Expression of arsenic resistance genes in the obligate anaerobe Bacteroides vulgatus ATCC 8482, a gut microbiome bacterium. Anaerobe 39: 117-123, 2016.

39. Cohen E, Ophir I and Shaul YB: Induced differentiation in HT29, a human colon adenocarcinoma cell line. J Cell Sci 112 (Pt 16): 2657-2666, 1999.

40. Kuroda K, Fukuda T, Krstic-Demonacos M, Demonacos C, Okumura K, Isogai H, Hayashi M, Saito K and Isogai E: miR-663a regulates growth of colon cancer cells, after administration of antimicrobial peptides, by targeting CXCR4-p21 pathway. BMC Cancer 17: 33, 2017.

41. Isogai E, Isogai H, Kimura K, Hayashi S, Kubota T, Fujii N and Takeshi K: Role of tumor necrosis factor alpha in gnotobiotic mice infected with an Escherichia coli O157:H7 strain. Infect Immun 66: 197-202, 1998.

42. Koopman G, Reutelingsperger CP, Kuijten GA, Keehnen RM, Pals ST and van Oers MH: Annexin V for flow cytometric detection of phosphatidylserine expression on B cells undergoing apoptosis. Blood 84: 1415-1420, 1994.

43. Zelenin AV, Poletaev AI, Stepanova NG, Barsky VE, Kolesnikov VA, Nikitin SM, Zhuze AL and Gnutchev NV: 7-Amino-actinomycin D as a specific fluorophore for DNA content analysis by laser flow cytometry. Cytometry 5: 348-354, 1984.

44. Eaton KA, Fontaine C, Friedman DI, Conti N and Alteri CJ: Pathogenesis of colitis in germ-free mice infected with EHEC O157:H7. Vet Pathol 54: 710-719, 2017

45. Bamba T, Matsuda H, Endo M and Fujiyama Y: The pathogenic role of Bacteroides vulgatus in patients with ulcerative colitis. J Gastroenterol 30 (Suppl 8): 45-47, 1995.

46. Frankel G, Phillips AD, Rosenshine I, Dougan G, Kaper JB and Knutton S: Enteropathogenic and enterohaemorrhagic Escherichia coli: More subversive elements. Mol Microbiol 30: 911-921, 1998.

47. Pifer R and Sperandio V: The interplay between the microbiota and enterohemorrhagic Escherichia coli. Microbiol Spectr 2: 2014.

This work is licensed under a Creative Commons Attribution-NonCommercial-NoDerivatives 4.0 International (CC BY-NC-ND 4.0) License. 